\title{
Characterization of the ISDB-Tb critical spectrum mask
}

\author{
Pablo N. De Césare, Marcelo Tenorio \\ National Institute of Industrial Technology (INTI), Radiocommunication Laboratory, Av Gral. Paz 5445, San Martín, Buenos Aires Argentina
}

Non-linearity in the ISDB-T transmission chain causes intermodulation products that widens the spectrum emission and should be taken into account when assigning frequency channels. The characterization of the transmission spectrum mask is one of the most important measurements in order to achieve the best use of the electromagnetic spectrum. The use of critical mask defined in [1] allows allocations of co-site adjacent channels for an efficient use of the electromagnetic spectrum that is a finite and limited resource. This paper discusses different test procedures using spectrum analyzers and dedicated digital TV analyzers in order to measure the ISDB-T transmission mask.

Keywords: ISDB-T, spectrum mask, intermodulation, spectrum analyzer

Citation: Pablo N. De Césare, Marcelo Tenorio Characterization of the ISDB-Tb critical spectrum mask, Acta IMEKO, vol. 1, no. 1, article 10, July 2012, identifier: IMEKO-ACTA-01(2012)-01-10

Editor: Pedro Ramos, Instituto de Telecomunicações and Instituto Superior Técnico/Universidade Técnica de Lisboa, Portugal

Received January $9^{\text {th }}, 2012$; In final form July $6^{\text {th }}, 2012$; Published July 2012

Copyright: () 2012 IMEKO. This is an open-access article distributed under the terms of the Creative Commons Attribution 3.0 License, which permits unrestricted use, distribution, and reproduction in any medium, provided the original author and source are credited

Funding: No information available

Corresponding author: Pablo De Césare, e-mail: decesare@inti.gob.ar

\section{INTRODUCTION}

The transmission spectrum of the Integrated Services Digital Broadcasting-Terrestrial (ISDB-T) signal [1] consists of 13 successive OFDM segments. The nature of OFDM modulation is to send the information parallelized in thousands of modulated carriers very close to each other, obtained through an IFFT algorithm. These carriers are then amplified by a power amplifier chain with a non-linear behaviour that generates intermodulation products that increase the out of band emission interfering with the adjacent channels and also degrading signal quality due to inter-carrier interference.

Reducing out-of-band emissions demands the incorporation of an external filter at the output of the power transmitter to eliminate the intermodulation products generated [2][3].

As defined in the Brazilian digital terrestrial television standard ABNT NBR 15601, there are three different spectrum masks: non-critical; sub-critical and critical. The difference between them are the attenuation of the out-side emission being the most difficult to achieve and test.

Transmission spectrum masks are commonly tested with spectrum analysers, but in ISDB-T, the requirements are too high and more sophisticated measurement test methods must be incorporated into digital TV analysers.

In this paper the transmission spectrum mask measurement as an alternative methodology is proposed and compared with a multi-propose spectrum analyser and other dedicated digital TV analysers, the characteristics of the test equipment required is described and the uncertainty calculation for the proposed method is included.

\section{TEST ANALISYS}

\subsection{ISDB-T signal analysis}

ISDB-T modulation can be configured to operate in three different modes: Mode 1 or $2 \mathrm{k}$, Mode 2 or $4 \mathrm{k}$ and Mode 3 or $8 \mathrm{k}$ that modify the number of carriers per OFDM segment. The frequency bandwidth shall be $5.7 \mathrm{MHz}$ when the OFDM carrier bandwidth is $5.572 \mathrm{MHz}$ with $4 \mathrm{kHz}$ spacing between carrier frequencies in Mode 1. This bandwidth shall apply regardless of the mode which is chosen, and selected to ensure that the bandwidth of $5.610 \mathrm{MHz}$ has a gap where each carrier of the uppermost and lowermost frequencies in the $5.572 \mathrm{MHz}$ bandwidth includes $99 \%$ of the energy.

According with standards ABNT NBR 15601 and ARIB STD-B31 if the spectrum mask is tested with a resolution bandwidth of $10 \mathrm{kHz}$, the power density is reduced by

$10 \log \left(\frac{5.572 \mathrm{MHz}}{10 \mathrm{kHz}}\right)=27.46 \mathrm{~dB}$.

ABNT NBR 15601 Table 41 defines the limits of the outof-band emission indicating the attenuations in relation to the transmitter average power. The final purpose of this test it to characterize the power density distributions, thus the limits 


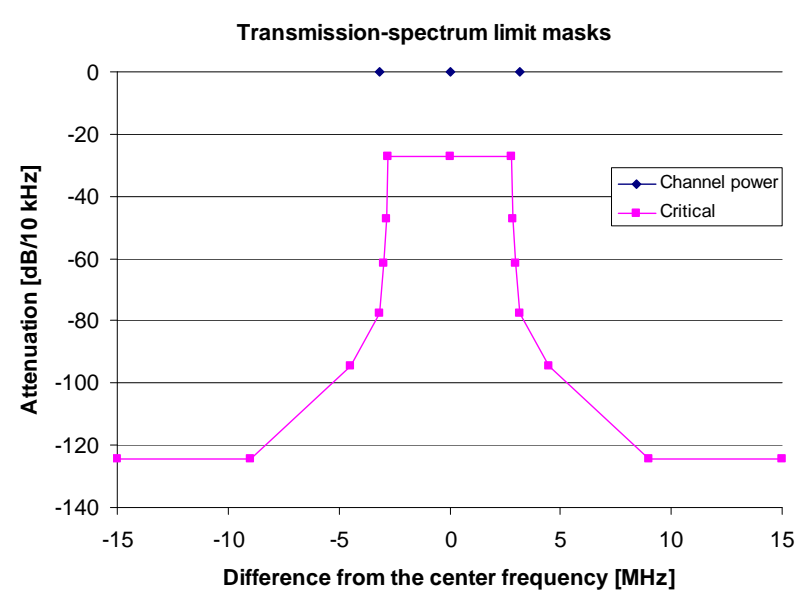

Figure 1. ISDB-T critical mask.

given in [1] should be specified as attenuation in relation to the power density at $10 \mathrm{kHz}$ as shown in Figure 1.

\subsection{Two tone Intermodulation phenomena}

A two tone intermodulation phenomenon can be observed when two $\mathrm{CW}$ sources are combined at the input of an amplifier and their frequencies are inside the passband of the device being tested. Nonlinearities in the amplifier will lead to intermodulation products of the form $\left(N \omega_{1}-M \omega_{2}\right)$. The components $\left(2 \omega_{1}-\omega_{2}\right),\left(2 \omega_{2}-\omega_{1}\right)$ and $\left(3 \omega_{1}-2 \omega_{2}\right),\left(3 \omega_{2}-2 \omega_{1}\right)$ are known respectively as third and fifth order intermodulation products and their frequencies and levels are close to the fundamental tones $\omega_{1}$ and $\omega_{2}$. Higher order products are generally negligible in comparison.

This phenomenon is also present in the testing equipment and is one of the limits of the available dynamic range. The input mixer of a spectrum analyser is a non-linear device, so it always generates distortion by itself. Most spectrum analysers use diode mixers and their current intensity can be expressed as

$$
i=I_{s} \cdot\left(e^{\frac{q v}{k t}}-1\right),
$$

where $I_{s}$ is the diode's saturation current, $q$ is the electron charge $\left(1.60 \times 10^{-19} \mathrm{C}\right)$, $v$ is the instantaneous voltage,

$k$ is the Boltzmann's constant $\left(1.38 \times 10^{-23}\right.$ joule $\left./{ }^{\circ} \mathrm{K}\right)$, $T$ is the temperature in degrees Kelvin.

Expanding into a power series leads to

$i=I_{s}\left(k_{1} v+k_{2} v^{2}+k_{3} v^{3}+\ldots\right)$.

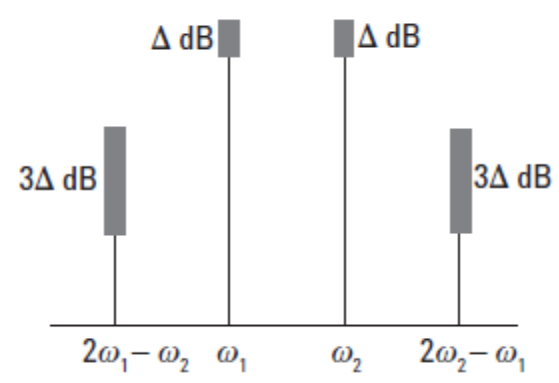

Figure 2. Two-tone intermodulation.
Consider that two tones and the local oscillator are input into the mixer. In this case the input voltage is given by

$v=V_{L O} \sin \left(\omega_{L O} t\right)+V_{1} \sin \left(\omega_{1} t\right)+V_{2} \sin \left(\omega_{2} t\right)$.

The following unwanted mixing products are also generated in the output mixer:

$$
\begin{aligned}
& \left(k_{4} / 8\right) V_{L O} V_{1}^{2} V_{2} \cos \left[\omega_{L O}-\left(2 \omega_{1}-\omega_{2}\right)\right] t \\
& \left(k_{4} / 8\right) V_{L O} V_{1} V_{2}^{2} \cos \left[\omega_{L O}-\left(2 \omega_{2}-\omega_{1}\right] t\right.
\end{aligned}
$$

where

$$
k_{4}=\frac{\left(\frac{q}{k T}\right)^{4}}{4 !}
$$

If $V_{1}$ and $V_{2}$ have the same amplitude, their products can be considered as cubic terms. The third order products rise at rate $3 \mathrm{~dB} / \mathrm{dB}$ as is shown in Figure 2.

\subsection{Instrument available dynamic range}

Dynamic range is the ratio, expressed in $\mathrm{dB}$, of the largest to the smallest signals simultaneously present at the input of the instrument that allows measurement of the smaller signal to a given degree of uncertainty.

There are three factors that limit the dynamic range: internal noise, internal intermodulation performance and the phase noise of a local oscillator.

The instrument internally generates noise and distortion that affects the measurement's accuracy. Spectrum analysers' noise floor is described by DANL and signals below this level cannot be seen. The input attenuator strongly affects the sensitivity of the analyser to display low level signals by attenuating the input signal and reducing the signal-to-noise ratio (SNR). Resolution bandwidth also affects SNR. The total noise power is determined by the width of the IF filter. The noise level displayed varies following the relation

$N_{1,2}=10 \log \left(\frac{R B W_{2}}{R B W_{1}}\right)$.

Since DANL is often referred to a specific IF-filter bandwidth, it is easy to obtain the displayed noise for any IF-filter bandwidth. ISDB-T spectrum mask measurement

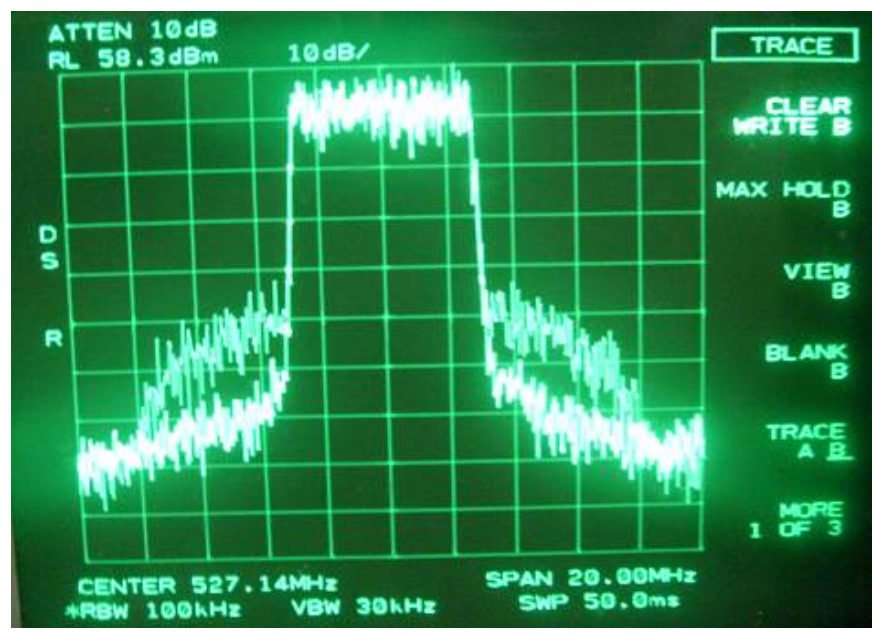

Figure. 3 Spectral growth caused by the input mixer level. 
Table 1. Instruments' specifications.

\begin{tabular}{|c|c|c|c|c|c|c|c|}
\hline \multirow{2}{*}{ Parameter } & \multirow{2}{*}{ HF 6564} & \multicolumn{2}{|c|}{ MS8911B } & \multicolumn{2}{|c|}{ RQS ETH } & \multicolumn{2}{|c|}{ RQSETL } \\
\hline & & pre-amp on & pre-amp off & RF presel on & RF presel off & pre-amp on & pre-amp off \\
\hline TOl [dBm] & 11 & $-\ldots$ & 10 & -6 & 7 & -- & 12 \\
\hline DANL [ABm] & -150 & -150 & -123 & -165 & -156 & -166 & -140 \\
\hline
\end{tabular}

defines a $10 \mathrm{kHz}$ IF-filter.

The unwanted distortion products generated by the input mixer fall at the same frequencies as the distortion products under measure on the ISDB-T input signal. The effect of the intermodulation can be seen as a spectral growth usually described as "spectrum shoulders" as can be seen in the top trace of Figure 3.

The phase relationship generates additions and cancelations between the generated intermodulation products and the signal that we want to measure. The lack of knowledge of the phase relationship between them is a source of uncertainty that also depends on their amplitude relationship through the relation

$$
\text { error }_{\text {Internal intermodulation }}=20 \log \left(1 \pm 10^{\frac{d}{20}}\right) \text {, }
$$

where $d$ is the difference in $\mathrm{dB}$ between the amplitude of the intermodulation products generated internally and the amplitude of the intermodulation of the incoming signal. The probability function distribution can be assumed as being rectangular.

The third order performance is given by the Third Order Intercept point (TOI) and represents the mixer level at which the internally generated intermodulation would be equal to the fundamental tones. This point is obtained by sweeping the levels of the fundamental tones $\omega_{1}$ and $\omega_{2}$ and observing the levels of the third order components as a function of the input power level.

The dynamic range can be plotted as a function of the mixer input signal level. Low levels reduce the SNR and causes lower intermodulation products. High levels lead to more noise immunity but increase the intermodulation products. Figure 4 shows the HP8564 [4] available dynamic range for ISDB-T spectrum mask, where $78 \mathrm{~dB}$ is the best condition obtained for an input level of $-27 \mathrm{dBm}$.

As was shown in Figure 1, the required dynamic range for transmission spectrum mask is obtained by addition of the total power channel to the power density in a $10 \mathrm{kHz}$ band and the highest attenuation defined in [1]:

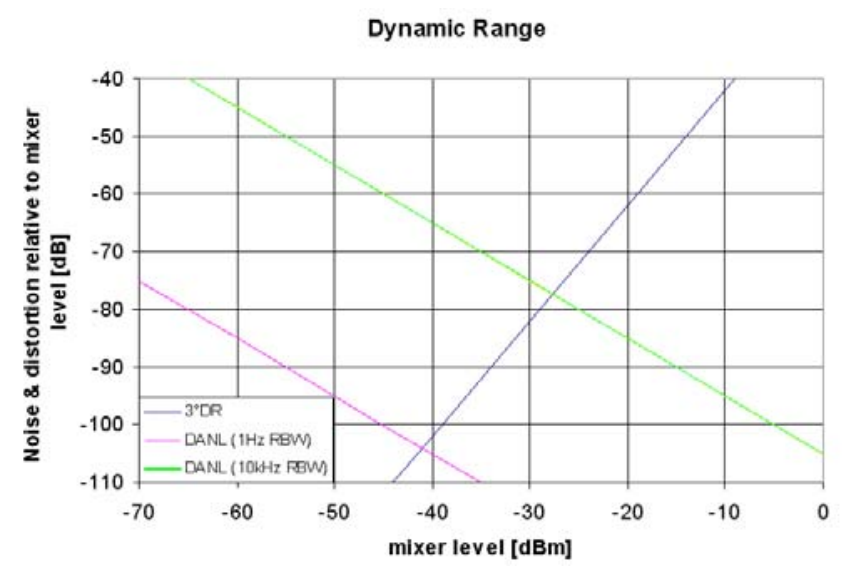

Figure 4. HP8564 dynamic range.

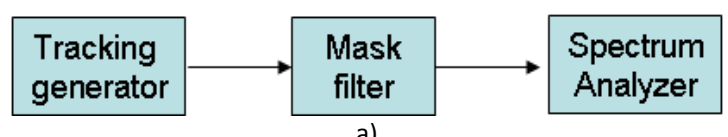

a)

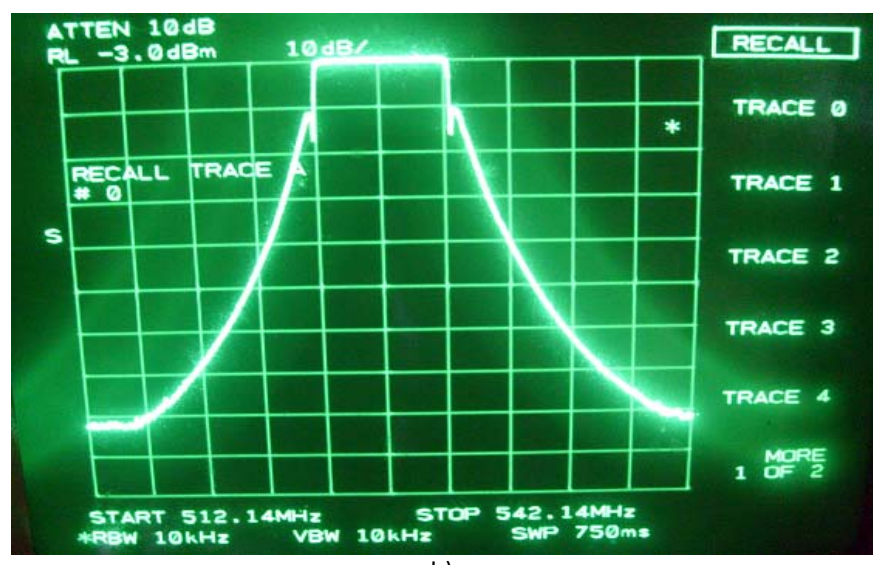

b)

Figure 5. Filter characterization a) block diagram and b) characterization trace.

Required dynamic range $=27.46 \mathrm{~dB}+97 \mathrm{~dB}=124.46 \mathrm{~dB}$

Actually, there is no available spectrum analyser with a dynamic range of $124.46 \mathrm{~dB}$.

Most digital TV analysers have been equipped to perform the spectrum transmission mask test. However yhey do not have the better TOI level and the lower DANL required. They only incorporate the facility to add the spectrum emission with the filter mask response.

Table 1 gives a comparison between a spectrum analyser HP8564 [5] and the digital TV analysers Anritsu MS8911B [5] and Rohde \& Schwarz ETH [6] and ETL [7].

\section{TEST PROCEDURE}

\subsection{Using a spectrum analyser}

To solve the excessive dynamic range requirement, out of band emissions can be tested by measuring the ISDB-T signal before filter mask and the filter response separately and then multiply both curves (or add them if they are expressed in $\mathrm{dB}$ ).

Figure $5 \mathrm{a}$ shows the filter characterization block diagram using a tracking generator synchronized with a spectrum analyser using the same setting defined in ABNT NBR 15601.

The filter characterization should be saved in an internal trace memory as Figure $5 b$ shows, where it is necessary that the top of the trace has the same Reference Level value of the spectrum analyser.

Figure 6 shows one of the possible block diagrams of the ISDB-T signal measurement system. The directional coupler before the mask filter must be previously characterized. To

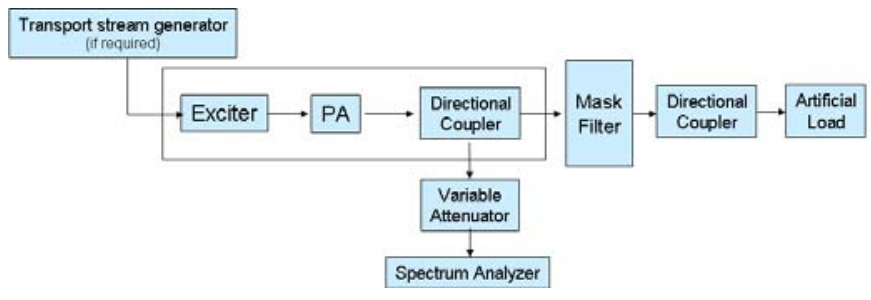

Figure 6. ISDB-T characterization block diagram. 


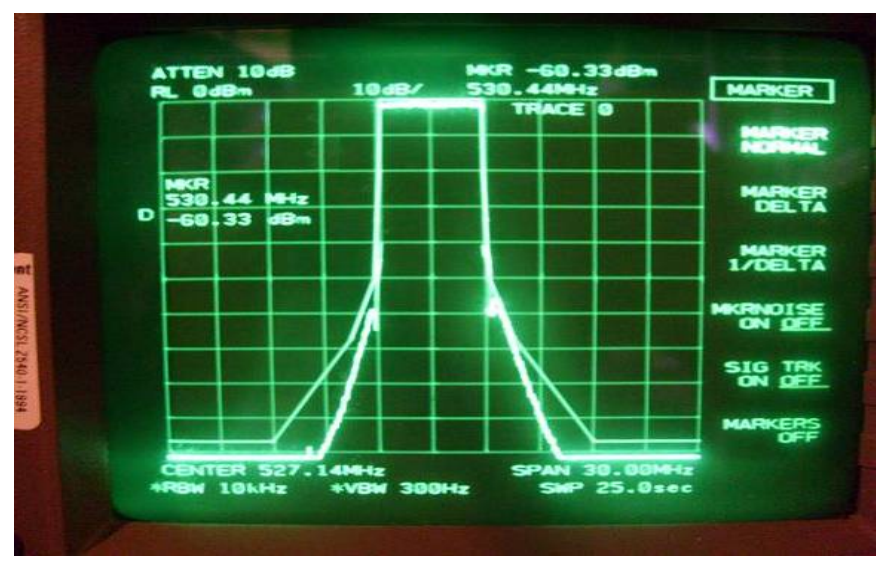

Figure 7. Transmission spectrum mask result.

obtain the best dynamic range it is necessary to add internal and external attenuation. Insufficient attenuation will cause intermodulation products close to the signal under test and an excessive one will increase the noise level. In practice it is desirable to adjust the attenuation in $1 \mathrm{~dB}$ steps until one obtains the best dynamic range.

Most spectrum analysers have many functions like the addition and subtraction of traces. The peak power density should have the same value as the reference level of the spectrum analyser.

When emissions cannot be measured due to the dynamic range, it is possible to recall the filter curve from an auxiliary trace and add it with the ISDB-T spectrum obtained before the mask filter as is shown in Figure 7.

Filter correction is very important for frequencies of $\pm 3 \mathrm{MHz}$ from the centre frequency.

In offset of $\pm 3 \mathrm{MHz}$ from the centre frequency the available dynamic range should be enough to determine the compliance of the transmission spectrum mask, but results with lower uncertainties can be obtained applying the filter corrections only out of these limits with the configuration shown in Figure 6.

Between $\pm 3 \mathrm{MHz}$ from the centre frequency lower uncertainties are obtained with the block diagram shown in Figure 8, without any correction of the filter transference.

\subsection{Using dedicated DTV analysers}

When using Anritsu MS8911B with option 030 for ISDB-T analysis a pre-load default filter response can be used.

Comparison between the MS8911B pre-load default filter ant that of a commercial RFS [5] response is shown in Figure 9.

The ETH TV analyser from Rohde \& Schwarz has an integrated tracking generator for filter characterization that allows saving to an internal trace.

The ETL TV analyser from Rohde \& Schwarz also has an

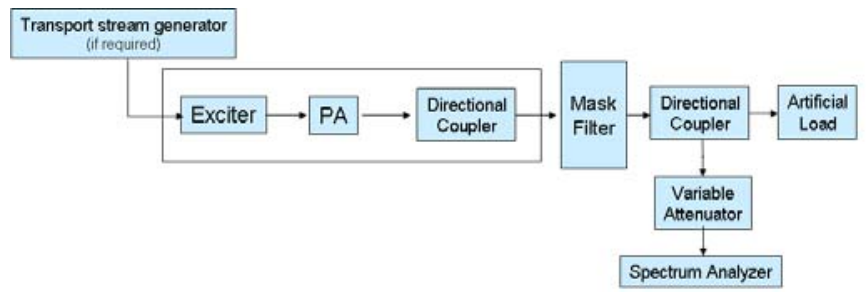

Figure 8. ISDB-T characterization block diagram between the $\pm 3 \mathrm{MHz}$ from the centre frequency.

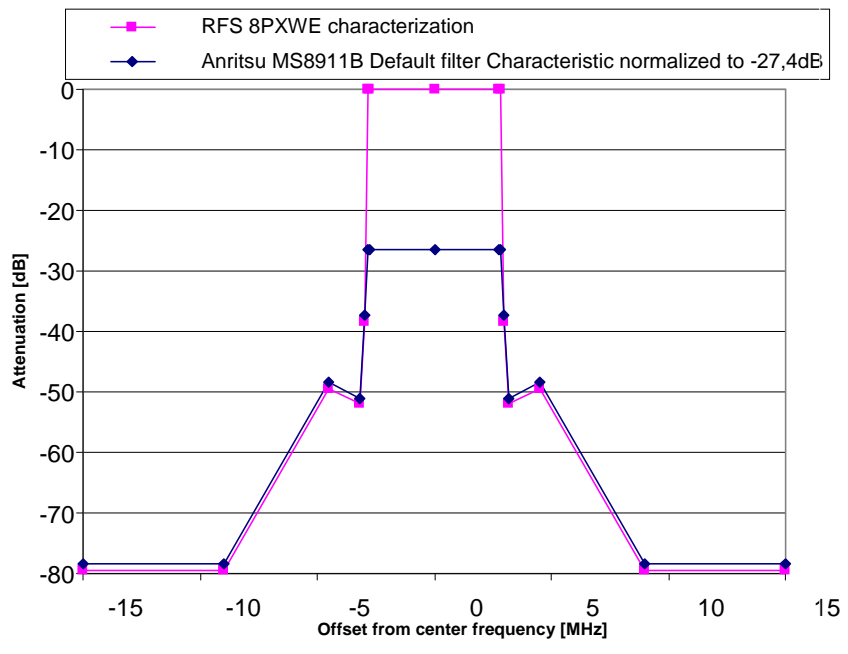

Figure 9. Anritsu 8911B default filter comparison.

integrated tracking generator for filter characterization but the filter response should be manually entered into a register.

\section{UNCERTAINTY ANALISYS}

\subsection{Uncertainty due to amplitude accuracy}

When the signal under test is applied to the instrument, the first source of uncertainty is given by impedance mismatch which causes the incident and reflected signals to add constructively or destructively. This causes the signal received by the analyser to be larger or smaller than the original one. This measurement is made with the same attenuator settings so the input attenuation switching uncertainty does not need to be considered. The input signal is mixed with the local oscillator and their flatness contributes to the frequency response uncertainty. Spectrum analysers have a band switching uncertainty but in measurements with a $30 \mathrm{MHz}$ span they do not usually need to be added. After the input signal is converted to an IF, it passes through the IF gain amplifier and IF attenuator that references the input signal amplitudes to the reference level. Reference level accuracy and resolution bandwidth switching do not add uncertainty in relative measurements such as spectrum mask, but the display scale fidelity should be included.

In Table 2 the sources of uncertainties, in relative measurement using spectrum analyser, are summarized.

Uncertainty due to Impedance mismatch can be calculated in the same way like power measurements [8][9].The systematic error is $1-\left|\Gamma_{L}\right|^{2}$ while the limits of mismatch uncertainty are $\pm 2\left|\Gamma_{G}\right|\left|\Gamma_{L}\right|$ caused by the lack of the phase difference between $\Gamma_{G}$ and $\Gamma_{L}$. In most cases, uncertainty due to mismatch is relatively small.

Table 2. Amplitude uncertainty in relative measurements.

\begin{tabular}{ccc}
\hline Source of uncertainty & Probability distribution & Divisor \\
\hline Impedance mismatch & U-shape & $\sqrt{2}$ \\
Frequency response & rectangular & $\sqrt{3}$ \\
Display scale fidelity & rectangular & $\sqrt{3}$ \\
\hline
\end{tabular}




\subsection{Uncertainty due to filter characterization}

Following the connections described in Figure 5a, filter characterization uncertainty will include the same sources described in Table 2, in addition with the frequency response of the tracking generator and mismatch in the input and output ports. That implies that the filter response trace, like Figure $5 \mathrm{~b}$ shows, is obtained with a given level of uncertainty that will be carried out until the final result. The attenuation of a filter inserted between a generator and a spectrum analyser that are not perfectly matched [3], has a standard deviation of

Table 3. Amplitude uncertainty in filter characterization

\begin{tabular}{lcc}
\hline Source of uncertainty & Probability distribution & Divisor \\
\hline Uncertainty for filter mismatch & normal & 1 \\
Generator Amplitude linearity & rectangular & $\sqrt{3}$ \\
Display scale fidelity & rectangular & $\sqrt{3}$ \\
Frequency response & rectangular & $\sqrt{3}$ \\
\hline
\end{tabular}

Table 4. Devices under test and test instruments.

\begin{tabular}{ll}
\hline ISDB-T transmitter & NEC DTL-10/1R6P 1kW UHF DIGITAL TV \\
& TRANSMITTER SYSTEM \\
Output filter & RFS 8PXWE \\
Spectrum analyser & HP8564E \\
Sweep generator & R\&S SMP02 \\
Variable attenuator 1 dB step & HP84904L \\
\hline
\end{tabular}

Table 5. Internal intermodulation error calculation.

\begin{tabular}{lc}
\hline Analyzer Parameter & Value \\
\hline Reference level $[\mathrm{dBm}]$ & -26.7 \\
Internal attenuator $[\mathrm{dB}]$ & 30 \\
Power/Power Density [dB] & 27.46 \\
Mixer level [dBm] & -29.24 \\
Available dynamic range $[\mathrm{dB}]$ & -78 \\
$\mathrm{~d}[\mathrm{~dB}]$ & 18 \\
error internal intermodulation $_{\text {[dB] }}$ & 1.1 \\
\hline
\end{tabular}

Table 6. Transmission mask measurement uncertainty for $\pm 3.5 \mathrm{MHz}$ offset from the centre frequency.

\begin{tabular}{lccccc}
\hline $\begin{array}{l}\text { Source of } \\
\text { uncertainty }\end{array}$ & $\begin{array}{c}\text { Value } \\
{[\mathrm{dB}]}\end{array}$ & $\begin{array}{c}\text { Probability } \\
\text { distribution }\end{array}$ & Divisor & $\begin{array}{c}\boldsymbol{u}_{\boldsymbol{i}} \\
{[\mathrm{dB}]}\end{array}$ & $\boldsymbol{v}_{\text {eff }}$ \\
\hline $\begin{array}{l}\text { Impedance } \\
\text { mismatch }\end{array}$ & 0.12 & U-shape & $\sqrt{2}$ & 0.08 & $\infty$ \\
$\begin{array}{l}\text { Frequency } \\
\text { response }\end{array}$ & 0.80 & rectangular & $\sqrt{3}$ & 0.46 & $\infty$ \\
$\begin{array}{l}\text { Display scale } \\
\text { fidelity }\end{array}$ & 0.85 & rectangular & $\sqrt{3}$ & 0.49 & $\infty$ \\
$\begin{array}{l}\text { Internal } \\
\text { intermodulation }\end{array}$ & 1.10 & rectangular & $\sqrt{3}$ & 0.64 & $\infty$ \\
$\begin{array}{l}\text { Combined standard } \\
\text { uncertainty }\end{array}$ & - & normal & - & 0.93 & $>1000$ \\
$\begin{array}{l}\text { Expanded } \\
\text { uncertainty }\end{array}$ & - & $K=2$ & - & 1.86 & $>1000$ \\
\hline
\end{tabular}

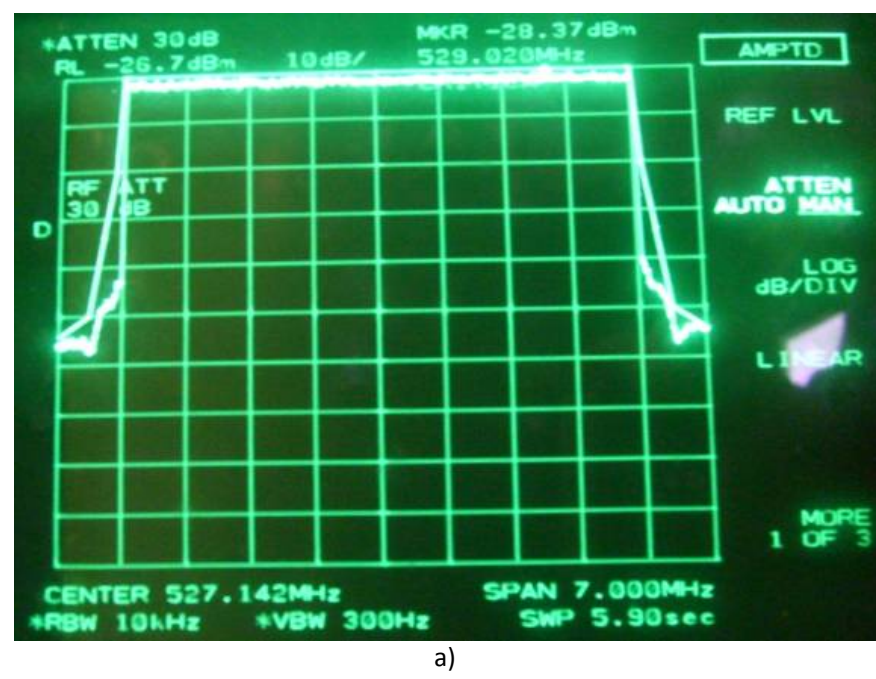

Transmission spectrum mask

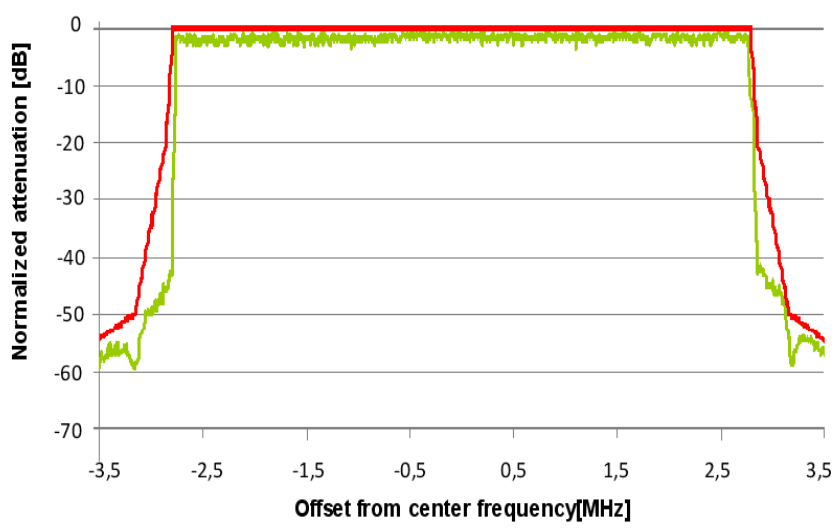

b)

Figure 10. Critical mask measurement between $\pm 3.5 \mathrm{MHz}$ from the channel centre frequency.

mismatch, $M[\mathrm{~dB}]$, which can be approximated by

$M[\mathrm{~dB}] \approx \frac{8.686}{\sqrt{2}}\left[\begin{array}{l}\left|\Gamma_{G}\right|^{2} \cdot\left|S_{11 f}\right|^{2}+\left|\Gamma_{L}\right|^{2} \cdot\left|S_{22 f}\right|^{2}+ \\ +\left|\Gamma_{G}\right|^{2} \cdot\left|\Gamma_{L}\right|^{2}\left(1+\left|S_{21 f}\right|^{4}\right)\end{array}\right]^{0.5}$

where $S_{11_{f}}$ and $S_{21_{f}}$ can be obtained from the filter specifications [5].

Table 3 shows the uncertainty sources of the filter characterization measurement.

\section{RESULTS}

The device under test and the instruments used during the test are show in Table 4.

\subsection{Measuring transmission spectrum mask after filter between $\pm 3.5 \mathrm{MHz}$ offset from centre frequency using spectrum analyser}

Figure $10 \mathrm{a}$ shows the transmission mask measurement measured as Figure 8 describes. Figure 10b represents the same information as a function of frequency offset from the centre frequency channel. On Table 6 the uncertainty budget is shown.

The internal intermodulation error shown in Table 5 is obtained using the spectrum analyser settings and the calculated available dynamic range. 


\subsection{Uncertainty budget}

The uncertainty budget for the transmission mask can be seen in Table 6 for the case of $\pm 3.5 \mathrm{MHz}$ offset from the centre frequency.

\subsection{Measuring transmission spectrum mask before filter beside $\pm 3.5 \mathrm{MHz}$ offset from centre frequency using spectrum analyser}

For testing the transmission spectrum mask on frequencies offset higher than $\pm 3.5 \mathrm{MHz}$, two measurements must be done: filter characterization and spectrum emissions measures before the filter. The results of filter characterization measurement

Table 7. Filter characterization uncertainty.

\begin{tabular}{lccccc}
\hline $\begin{array}{l}\text { Source of } \\
\text { uncertainty }\end{array}$ & $\begin{array}{c}\text { Value } \\
{[\mathrm{dB}]}\end{array}$ & $\begin{array}{c}\text { Probability } \\
\text { distribution }\end{array}$ & Divisor & $\begin{array}{c}\boldsymbol{u}_{\boldsymbol{i}} \\
{[\mathrm{dB}]}\end{array}$ & $\boldsymbol{v}_{\text {eff }}$ \\
\hline $\begin{array}{l}\text { Filter } \\
\text { Impedance } \\
\text { mismatch }\end{array}$ & 0.31 & Normal & 1 & 0.31 & $\infty$ \\
$\begin{array}{l}\text { Generator } \\
\text { Amplitude } \\
\text { linearity }\end{array}$ & 0.60 & rectangular & $\sqrt{3}$ & 0.35 & $\infty$ \\
$\begin{array}{l}\text { Frequency } \\
\text { response }\end{array}$ & 0.80 & rectangular & $\sqrt{3}$ & 0.46 & $\infty$ \\
$\begin{array}{l}\text { Display scale } \\
\text { fidelity }\end{array}$ & 0.85 & rectangular & $\sqrt{3}$ & 0.49 & $\infty$
\end{tabular}

Combined

standard

normal

$0.74>1000$

uncertainty

\begin{tabular}{lll|lll}
$\begin{array}{l}\text { Expanded } \\
\text { uncertainty }\end{array}-$ & - & $K=2$ & - & 1.49 & $>1000$ \\
\hline
\end{tabular}

Table 8. Internal intermodulation error calculation.

\begin{tabular}{lc}
\hline Analyzer Parameter & Value \\
\hline Mixer level $[\mathrm{dBm}]$ & -29.24 \\
Available dynamic range $[\mathrm{dB}]$ & -78 \\
$\mathrm{~d}[\mathrm{~dB}]$ & 22 \\
error $_{\text {internal intermodulation }}[\mathrm{dB}]$ & 0.7 \\
\hline
\end{tabular}

Table 9. Transmission mask measurement uncertainty.

\begin{tabular}{lccccc}
\hline $\begin{array}{l}\text { Source of } \\
\text { uncertainty }\end{array}$ & $\begin{array}{c}\text { Value } \\
{[\mathrm{dB}]}\end{array}$ & $\begin{array}{c}\text { Probability } \\
\text { distribution }\end{array}$ & Divisor & $\begin{array}{c}\boldsymbol{u}_{\boldsymbol{i}} \\
{[\mathrm{dB}]}\end{array}$ & $\boldsymbol{v}_{\text {eff }}$ \\
\hline $\begin{array}{l}\text { Impedance } \\
\text { mismatch }\end{array}$ & 0.12 & U-shape & $\sqrt{2}$ & 0.08 & $\infty$ \\
$\begin{array}{l}\text { Frequency } \\
\text { response }\end{array}$ & 0.80 & rectangular & $\sqrt{3}$ & 0.46 & $\infty$ \\
$\begin{array}{l}\text { Display scale } \\
\text { fidelity }\end{array}$ & 0.85 & rectangular & $\sqrt{3}$ & 0.49 & $\infty$ \\
$\begin{array}{l}\text { Internal } \\
\text { intermodulation }\end{array}$ & 0.7 & rectangular & $\sqrt{3}$ & 0.20 & $\infty$ \\
$\begin{array}{l}\text { Filter } \\
\text { characterization }\end{array}$ & 0.74 & normal & 1 & 0.74 & $>1000$ \\
$\begin{array}{l}\text { Combined standard } \\
\text { uncertainty }\end{array}$ & - & normal & - & 1.11 & $>1000$ \\
$\begin{array}{l}\text { Expanded } \\
\text { uncertainty }\end{array}$ & - & $K=2$ & - & 2.22 & $>1000$ \\
\hline
\end{tabular}

following the connections described in Figure 5a, are shown in Figure 11 and the uncertainty budget on Table 7.

\subsection{Filter characterization uncertainty budget}

Figure 12 shows the filter characterization trace, the spectrum emission trace, measured before the filter and the result obtained as the addition of these two traces. The results are compared with the limits of the critical mask defined in [1].

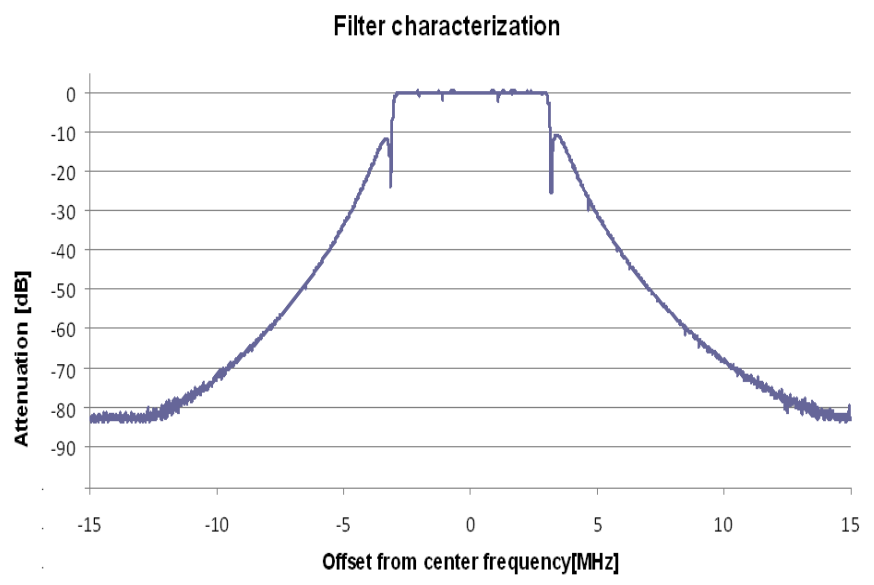

Figure 11. Filter characterization measurement.

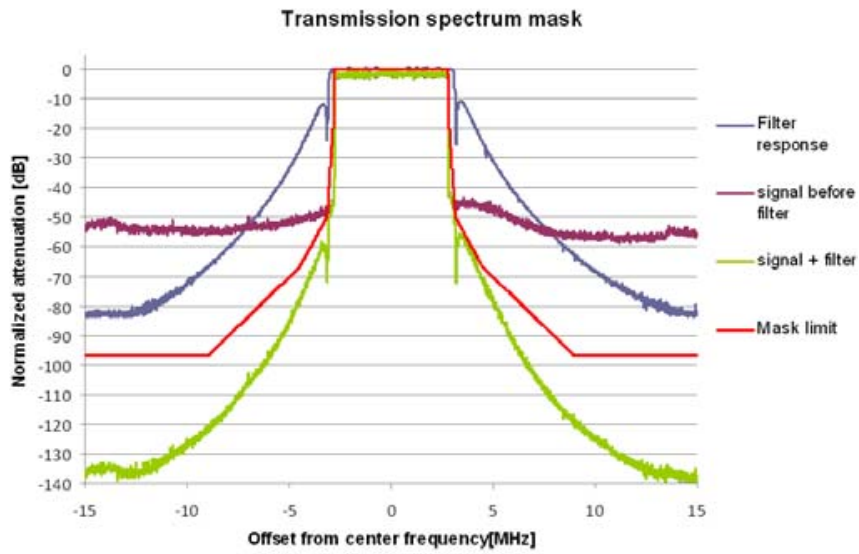

Figure 12. Transmission spectrum mask measurement results.

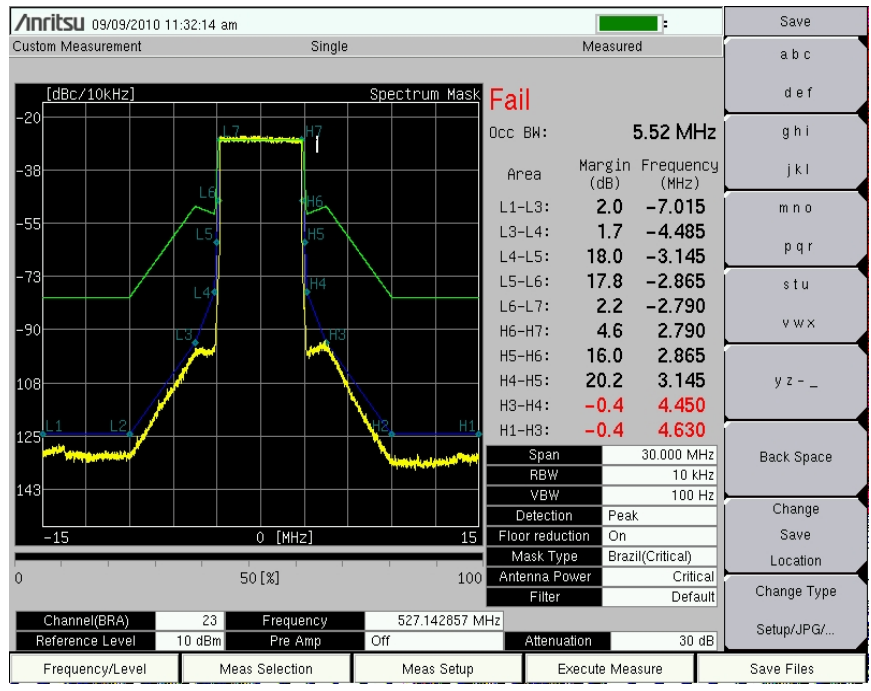

Figure 13. Transmission spectrum mask measurement results. 


\subsection{Uncertainty due to internal intermodulation}

To measure the ISDB-T signal before the filter, the available dynamic range is $22 \mathrm{~dB}$. Table 8 shows the spectrum analyser parameters and the obtained error generated by the internal intermodulation.

\subsection{Measuring transmission spectrum using ANRITSU MS8911B}

The results of critical mask transmission measurements using ANRITSU MS8911B are shown in Figure 13, where the filter characterization measurement described before was replaced by the default filter response pre-load.

\section{CONCLUSIONS}

It is possible to reduce measurement uncertainty of the transmission spectrum mask between $\pm 3.5 \mathrm{MHz}$ from the centre frequency using the available dynamic range when the internal intermodulation error is relative low.

Out of $\pm 3.5 \mathrm{MHz}$ from the centre frequency, where the requirement of dynamic range exceeds the available one, a filter response correction is applied and the results are obtained by addition the mask filter response to the ISDB-T signal measured before it. In this case, the uncertainty is higher due to the contribution of filter characterization uncertainty.

ISDB-T testers have the similar performance than multipurpose spectrum analyser for testing the transmission spectrum mask.

The use of pre-load default filter response gives a good approximation of the final measurement result but the results obtained should not be used for approval test being the mask filter characterization the more accurate method.

Digital TV analysers incorporate facilities to add the mask filter response to the ISDB-T signal but the main advantage of them are the base band analysis, allowing measurement like modulation error ratio (M.E.R.), echo pattern, imbalance I-Q, and bit error rate performance that characterize the signal quality.

\section{REFERENCES}

[1] ABNT NBR 15601A - Digital terrestrial television Transmission system (in Portuguese), Associação Brasileria de Normas Técnicas, 2007. ISBN: 978-85-07-00539-1.

[2] Hossein Yamini and Vijaya Kumar Devabhaktuni "CAD of Dual-Mode Elliptic Filters Exploiting Segmentation", 36 th European Microwave Conference, 10-15 Sept. 2006, pp. 560-563.

[3] RFS, Technical Data Sheet PXW Series.

[4] Agilent 8560 E-Series Spectrum Analysers product specification.

[5] Anritsu MS8911B product specification.

[6] Rohde \& Schwarz ETH product specification.

[7] Rohde \& Schwarz ETL product specification.

[8] I.A. Harris, F.L. Warner, "Re-examination of mismatch uncertainty when measuring microwave power and attenuation", IEE Proceedings, Part H - Microwaves, Optics and Antennas, vol. 128, pt. H, no. 1, February 1981, pp. 35-41.

[9] Glenn F. Engen, "Microwave Circuit Theory and Foundations of Microwave Metrology", IET 1992, ISBN 0-86341-287-4, pp. 33-83. 